\title{
Spark plasma sintering microscopic mechanisms of metallic systems: experiments and
}

simulations

Z. Trzaska ${ }^{1}$, C. Collard ${ }^{2}$, L. Durand ${ }^{2}$, A. Couret ${ }^{2}$, J.M. Chaix ${ }^{3}$, G. Fantozzi ${ }^{4}$, J.P. Monchoux²*.

${ }^{1}$ LSPM CNRS UPR 3407, Université Sorbonne Paris Cité, 99 avenue Jean-Baptiste Clément, 93430 Villetaneuse, France.

${ }^{2}$ CEMES CNRS UPR 8011, Université de Toulouse, 29 Rue Jeanne Marvig, 31055 Toulouse, France.

${ }^{3}$ SIMaP CNRS UMR 5266, INP Grenoble, 1130 rue de la piscine, 38402 Saint-Martin d'Hères, France.

${ }^{4}$ MATEIS CNRS UMR 5510, INSA Lyon, bât. Blaise Pascal, 69621 Villeurbanne, France.

*Corresponding author: monchoux@cemes.fr

\section{Abstract}

The microscopic densification mechanisms of metallic systems (TiAl, Ag-Zn) by spark plasma sintering (SPS) have been studied by simulations and experiments. Finite element simulations showed that, despite very high current densities at the necks between metallic powder particles $\left(\approx 5 \times 10^{4} \mathrm{~A} / \mathrm{cm}^{2}\right)$, only very limited Joule overheating can be expected at these locations $\left(<1^{\circ} \mathrm{C}\right)$, because of very fast heat diffusion. The microscopic plasticity mechanisms under these high electric currents have been studied by transmission electron microscopy. For this purpose, thin foils have been extracted by focused ion beam at the necks between TiAl powder particles. This is the first time, to our knowledge, that microscopic plasticity mechanisms at the necks between powder particles are investigated by TEM during 
densification of a metallic powder. Dislocation glide and climb mechanisms were identified, followed by recovery and recrystallization. The elementary mechanism kinetically controlling these phenomena is proposed to be bulk diffusion of $\mathrm{Al}$, which activation energy ( $360 \mathrm{~kJ} / \mathrm{mol}$ ) is close to the activation energy measured for densification (308 $\pm 20 \mathrm{~kJ} / \mathrm{mol}$ ). Comparisons of densification kinetics by SPS $\left(\approx 60-110 \mathrm{~A} / \mathrm{cm}^{2}\right)$ and by hot pressing $\left(0 \mathrm{~A} / \mathrm{cm}^{2}\right)$ showed no influence of current on these mechanisms. Finally, reaction experiments in the Ag-Zn system did not show any influence of very high currents $\left(>1000 \mathrm{~A} / \mathrm{cm}^{2}\right)$ on diffusion kinetics. Consequently, densification by SPS occurs by classical mechanisms not affected by the current.

Keywords: Spark plasma sintering; Plasticity; Diffusion/diffusivity; Electron microscopy; Intermetallic systems

\section{Introduction}

This study reports on the microscopic mechanisms involved in the fast densification of metallic powders submitted to high electric currents in the spark plasma sintering (SPS) technique. It aims at accounting for the very high densification [1] and reaction [2] rates, which can exceed 10 times the rates of conventional sintering techniques. We focus on metallic systems, to investigate the intrinsic role of strong currents, that is, any effect (e.g. electromigration, electroplasticity) other than the classical Joule heating. We address the question of the influence of current on both densification and reaction, which in metallic systems point on two distinct elementary mechanisms, respectively plasticity and diffusion. Many studies attribute the SPS efficiency to current related phenomena. The first one is local overheating at the particle necks, due to arcs and plasma [3-7] or due to localized Joule heating [5, 8-16]. A second one is the acceleration of elementary mechanisms by electromigration [17] and electroplasticity [18] effects. 
In the present paper, we address these questions by combining theoretical predictive finite element method (FEM) simulations, macroscopic studies and fine microstructure characterizations by scanning and transmission microscopies (SEM, TEM), using the focused ion beam (FIB) technique. In particular, plasticity and recrystallization phenomena at the necks between metallic powder particles have for the first time been investigated, to the best of our knowledge. In the previously cited works, no accurate microstructure characterizations were undertaken together with macroscopic measurements or to theoretical calculations. Thus, our approach allowed investigating the impact of strong electric currents on elementary plasticity and diffusion mechanisms, which are involved in densification and reaction mechanisms occurring in sintering. For plasticity studies, TiAl was selected, because this system exhibits well-defined plasticity mechanisms. For investigating diffusion, the Ag-Zn system was chosen in reason of its very high diffusion rates, which makes it suitable for the short durations of the SPS experiments, and because a study reported this system to be sensitive to intrinsic current effects [19].

\section{FEM simulations of local Joule overheating}

We first calculated the local current density which can be reached at the small contact areas between metallic powder particles, to simulate early sintering stages, and then deduced the local increase in temperature generated by this effect. In previous works of literature, strong increase in temperature at the contacts were calculated (up to $1050^{\circ} \mathrm{C}$ [16]). However, either heat conduction was not considered [5,8], or "large" (millimetric or centimetric) particles were modelled $[10,12-14,16]$. Therefore, to verify that these strong thermal gradients can be obtained in typical SPS conditions, we have modelled metallic particles of sizes usually employed in experiments ( $100 \mu \mathrm{m})$, and we have taken into account heat conduction. 
Current distribution and temperature fields in arrangements of metallic particles have been simulated using a multi-physic approach. The following coupled equations have been solved:

$$
\begin{gathered}
\nabla \cdot \nabla(V)=0 \\
\nabla \cdot(-k \nabla T)+\rho c_{p}\left(\frac{\partial T}{\partial t}\right)=Q \\
Q=\sigma(\nabla V)^{2}
\end{gathered}
$$

(with $V$ : electric potential, $k$ : thermal conductivity, $\rho$ : density, $c_{p}$ : thermal capacity, $\sigma$. electrical conductivity, $T$ : temperature and $t$ : time). Close-packed FCC particle arrangements have been meshed (Fig. 1). The number and the type of elements used in the modelling of the heat conduction and Joule heating problems (described below) are given in table 1. Mesh refinement was tested in order to check the dependency of the results with the meshing and the size of elements. Other simulation details, concerning notably the delicate meshing procedure at the necks, are discussed elsewhere [20].

Table 1 here.

Fig. 1 here.

We used TiAl properties, which were accurately measured in previous studies [21], and are representative of electrically and heat conducting metallic materials. The thermal conductivity $k=9.47+1.19 \times 10^{-2} T\left(\mathrm{~W} \cdot \mathrm{m}^{-1} \cdot \mathrm{K}^{-1}\right)$ [22] was used. However, because it is at the moment difficult to evaluate the influence of insulating oxide layers at the surface of the powder particles on the local electrical properties, we have considered perfect electrical contacts between the particles.

In the Joule heating problem, at $t=0$, the simulated particle arrangement is submitted to a constant electric field of $15 \mathrm{~V} / \mathrm{m}$, which is close to experimental values. Fig. 2a shows an example of current density map in the particles at $t=36 \mathrm{~s}$ for contact size $r / R=0.06$ ( $r$ and $R$ 
being the neck and particle radii, respectively). Other examples of calculations, and a discussion of the repartition of the current within the particles, can be found in [20]. We present here the main results. An average current density of $500 \mathrm{~A} / \mathrm{cm}^{2}$ is calculated, which is in the order of magnitude of experimental values $\left(\approx 100 \mathrm{~A} / \mathrm{cm}^{2}[23]\right)$. However, contact resistances between the powder particles were not considered in the simulations. Therefore, the experimental values cannot be accurately reproduced. But, the striking feature in Fig. 2a (bottom) is the very high current densities (up to $5 \times 10^{4} \mathrm{~A} / \mathrm{cm}^{2}$ ) which can be reached at the particle contacts. This obviously results from the narrowed sections through which the current flows in the neck region (striction). Similar result was previously obtained [10]. Surprisingly, despite this strong inhomogeneity of the current density, the resulting temperature distribution is quasi uniform (Fig. 2b): the temperature, which is $987^{\circ} \mathrm{C}$ at particles centers, is less than $1^{\circ} \mathrm{C}$ higher in the neck regions. To account for this unexpected result, the effect of thermal conductivity alone has been assessed, in a reference case without the Joule heating (heat conduction problem). The details are given in [20]. The calculations simulate the case when $1000^{\circ} \mathrm{C}$ temperature step is imposed at the contacts of single particles $100 \mu \mathrm{m}$ in diameter at $t \approx 0$ (Fig. 3a). In this case, it takes only $4 \times 10^{-3} \mathrm{~s}$ for the temperature to be homogenized within less than $1^{\circ} \mathrm{C}$ in the particle (Fig. 3b, bottom). This shows that heat transfer is very fast for this characteristic length scales $(100 \mu \mathrm{m})$, which corresponds to experimental sizes of powder particles. Consequently, no significant thermal gradients in the particles can take place, even in the case of strong local heating, produced by high concentrations of current or other phenomena (Fig. 2a). Indeed, these calculations also simulate the case where an instantaneous localized heat production occurs by phenomena like arcs and plasma, or by dielectric breakdown of superficial oxide layers. In all cases, the intense localized heat produced by these phenomena is redistributed uniformly in the particles within milliseconds. Moreover, the absence of significant thermal gradients between necks and particle centers found in our study differs from the conclusions of Kuz'mov et al. 
[15], who modelled the effect of local heating due surface oxide films contact resistances on $10 \mu \mathrm{m}$ diameter $\mathrm{Cu}$ particles. These authors calculated high stationary thermal gradients $\left(10^{6} \mathrm{~K} / \mathrm{m}\right)$ but in quite different conditions: the particle heating was not considered, and the high thermal flows implied far higher heating rates than the ones considered in the present paper.

Fig. 2 here.

Fig. 3 here.

To verify the conclusions of our simulations, the $\gamma \rightarrow \alpha$ phase transition in TiAl, which gives a transition from equiaxed to lamellar microstructures at $1335^{\circ} \mathrm{C}$ (Fig. 4a-b), was used as an internal local thermometer. In case of significant overheating at the necks between the powder particles, the microstructure would locally change from equiaxed to lamellar. Fig. 4c shows an example in which the microstructure remains equiaxed in the vicinity of the neck. This means that the temperature did not exceed $1335^{\circ} \mathrm{C}$ in this region. As the average processing temperature was $926^{\circ} \mathrm{C}$, the overheating is thus below about $400^{\circ} \mathrm{C}$. This experimental observation is another indication of the very probable absence of significant local overheating, which is coherent with the FEM calculations.

Fig. 4 here.

However, the relative neck/particle size r/R has a strong impact on the final, quasi uniform temperature reached in the particles. For example, in identical conditions (applied voltage, time, etc.), the final temperature is $550 \mathrm{~K}$ for $\mathrm{r} / \mathrm{R}=0.02$ and $1250 \mathrm{~K}$ of $\mathrm{r} / \mathrm{R}=0.06$ ( $\mathrm{r}$ and $\mathrm{R}$ being the neck and particle radii, respectively), as discussed in our previous work [20].

\section{Plasticity mechanisms under electric currents}

Although strong current concentrations at the necks between powder particles (Fig. 2a) cannot generate hot spots, they could enhance the microscopic plasticity mechanisms involved in densification. This phenomenon, referred to as electroplasticity [18], could be triggered by 
currents of the order of $10^{5} \mathrm{~A} / \mathrm{cm}^{2}$ according to theoretical estimates [24], that is, close to the values obtained at the necks between metallic powder particles $\left(\approx 5 \times 10^{4} \mathrm{~A} / \mathrm{cm}^{2}\right)$. Moreover, lower current densities $\left(\approx 10^{3} \mathrm{~A} / \mathrm{cm}^{2}\right)$ were considered sufficient to influence the recrystallization phenomena [25]. We have then observed at fine scale by SEM and TEM the plasticity and recrystallization mechanisms in these regions [26]. In particular, a careful procedure of extraction of TEM thin foils by focused ion beam (FIB) at the necks between the powder particles has been set-up. These experiments have been performed with powders annealed prior to densification, to start with equilibrated microstructures mainly constituted of recrystallized $\gamma$ grains and of a small fraction of $\alpha_{2}$ grains.

First, to characterize recrystallization phenomena, SEM observations in electron backscattered diffraction (EBSD) mode have been carried out. Fig. 5 shows grain size maps for SPS and hot pressing (HP) experiments, that is, for densification with and without current. It can be noted in both cases that many grains in the neck regions (arrows) are colored in blue, meaning that their size has been reduced. This can be interpreted as a recrystallization phenomenon, resulting from the intense plastic deformation of the neck region. Recrystallization thus occurs in presence of a current (SPS) or without current (HP). Then, it seems that, in the present case, high electric currents have little influence on this phenomenon.

Fig. 5 here.

Then, to better characterize the microscopic plasticity mechanisms and the influence of strong electric currents on them, TEM thin foils have been extracted by FIB in the neck regions (Fig. 6a). Fig. 6b shows an example of TEM investigation. Dislocations elongated along their Burgers vector $b$, which exhibited then a screw character, were unambiguously identified. Loops and debris were also frequently noticed. These types of dislocations are characteristic of glide mechanisms. Some examples of helix-shaped dislocations were also observed, with 
however less certainty. This observation, with other investigations showing dislocations arranged in sub-boundaries [26], indicated climb mechanisms, which involve diffusion. Thus, the elementary mechanism controlling densification was bulk diffusion of Al, which activation energy (360 kJ/mol [27]) was close to the activation energy measured for densification in TiAl (308 $\pm 20 \mathrm{~kJ} / \mathrm{mol}$ [23]). In addition to the observation of sub-boundaries, which indicated recovery, examples of recrystallization nuclei were observed [26], which accounted for the grain refinement observed in the neck regions (Fig. 5). In summary, the plasticity mechanisms appeared classical, without any influence of the current.

Fig. 6 here.

Even if the mechanisms are not modified, a possible impact of the current could be to increase their kinetics. This effect would not have been detected by TEM, because the morphology of dislocations with higher mobility would not change much. Thus, densification kinetics by SPS with currents of $\approx 60-110 \mathrm{~A} / \mathrm{cm}^{2}$ flowing through the samples have been compared with kinetics obtained by HP, that is, without current. The example given in Fig. 7 shows that the densification kinetics are close in the two techniques, the differences remaining within the experimental errors [23]. Thus, the electric current flowing through the sample does not exhibit any significant effect on the kinetics of the elementary plasticity mechanisms involved in densification.

Fig. 7 here.

\section{Diffusion under high electric currents}

As seen above, currents of $\approx 100 \mathrm{~A} / \mathrm{cm}^{2}$ (typical of the SPS experiments) do not modify or accelerate the plasticity mechanisms. Here, we have artificially increased the current density up to above $1000 \mathrm{~A} / \mathrm{cm}^{2}$, to exacerbate any potential effect of electric currents on elementary mechanisms. We have selected the Ag-Zn system, which was known to be sensitive to 
electromigration effects for currents of 200-1000 $100 \mathrm{~A} / \mathrm{cm}^{2}$ [19], and in which diffusivity is fast enough to allow carrying out the experiments with short temperature cycles (some minutes), typical of the SPS experiments. Note that electromigration phenomena have been observed with many other systems, as reported in Munir's review [17]. Diffusion couple experiments have been performed, using two special configurations (Fig. 8a). In the first one, the samples were insulated from the current by a polymer. In the second one, all the current was forced to flow through the samples. Moreover, the use of $\mathrm{Cu}$ electrodes permitted intensities of the order of $1000 \mathrm{~A} / \mathrm{cm}^{2}$ to be reached. Fig. 8b shows SEM micrographs of the reaction layers formed in the two configurations. It can be seen that their thickness is identical. This has been reproducibly obtained for many experiments, showing no influence of currents of the order of $1000 \mathrm{~A} / \mathrm{cm}^{2}$ on the diffusion mechanisms involved in the reaction phenomena in the Ag-Zn system [28].

Fig. 8 here.

\section{Conclusions}

This approach combining simulations and experiments has allowed investigating the influence of the electric current of the SPS on the microscopic mechanisms involved in densification of metallic powders. Finite element calculations show that, despite very high current density at the necks between the powder particles (values as high as $\approx 50000 \mathrm{~A} / \mathrm{cm}^{2}$ could be reached), the associated overheating is extremely limited $\left(<1^{\circ} \mathrm{C}\right)$. The simulations show that this results from the very fast heat diffusion at the scale of the powder particles. The microscopic plasticity mechanisms in the necks, where the current is the highest, have been investigated, notably using the FIB technique to extract TEM thin foils at the necks. Thus, for the first time, glide and climb deformation mechanisms, followed by recovery/recrystallization processes, have been observed, without obvious impact of the strong electric current. 
Consequently, the macroscopic densification kinetics were very close by SPS $\left(\approx 100 \mathrm{~A} / \mathrm{cm}^{2}\right)$ and by HP $\left(0 \mathrm{~A} / \mathrm{cm}^{2}\right)$. Moreover, increasing the current up to above $1000 \mathrm{~A} / \mathrm{cm}^{2}$ did not change the diffusion kinetics in reaction experiments in the Ag-Zn system. These results indicate that the SPS current $\left(\approx 100 \mathrm{~A} / \mathrm{cm}^{2}\right)$ is probably too low to trigger any intrinsic effect on the microscopic densification mechanisms of conducting metallic powders. In summary, densification of metallic powders by SPS involves classical metallurgical mechanisms, without influence of the current.

\section{Acknowledgements}

This work has been granted by the MF2-ANR-2011-PBS09-020 project of the French Agence Nationale de la Recherche. The SPS studies have been performed with the Sumitomo 2080 SPS machine of the Plateforme Nationale de Frittage Flash du CNRS (PNF2-CNRS, Paul Sabatier University, Toulouse, France).

\section{References}

[1] Shen Z, Johnson M, Zhao Z, Nygren M. Spark plasma sintering of alumina. J Am Ceram Soc. 2002; 85:1921-1927.

[2] Jouan G, Dollé M, Monchoux JP. Decoupling the effects of pressure and current in spark plasma sintering: synthesis of $\mathrm{Cu}_{0.9} \mathrm{~V}_{2} \mathrm{O}_{5}$. Solid State Ionics. 2013; 236:5-10.

[3] Tokita M. Development of large-size ceramic/metal bulk FGM fabricated by spark plasma sintering. Mater Sci Forum. 1999; 308-311:83-88.

[4] Omori M. Sintering, consolidation, reaction and crystal growth by the spark plasma system (SPS). Mater Sci Eng A. 2000; 287-183-188.

[5] Yanagisawa O, Kuramoto H, Matsugi K, Komatsu M. Observation of particle behavior in copper powder compact during pulsed electric discharge. Mater Sci Eng A. 2003; 350-184-189. 
[6] Chaim R. Electric field effects during spark plasma sintering of ceramic nanoparticles. J Mater Sci. 2013; 48-502-510.

[7] Saunders T, Grasso S, Reece MJ. Plasma formation during electric discharge (50 V) through conductive powder compacts. J Eur Ceram Soc. 2015; 35-871-877.

[8] Song X, Liu X, Zhang J. Neck formation and self-adjusting mechanism of neck growth of conducting powders in spark plasma sintering. J Am Ceram Soc. 2006; 89:494-500.

[9] Ji G, Grosdidier T, Bozzolo N, Launois S. The mechanisms of microstructure formation in a nanostructured oxide dispersion strengthened FeAl alloy obtained by spark plasma sintering. Intermetallics. 2007; 15:108-118.

[10] Frei JM, Anselmi-Tamburini U, Munir ZA. Current effects on neck growth in the sintering of copper spheres to copper plates by the pulsed electric current method. J Appl Phys. 2007; 101:114914.

[11] Nowak S, Perrière L, Dembinski L, Tusseau-Nenez S, Champion Y. Approach of the spark plasma sintering mechanism in $\mathrm{Zr}_{57} \mathrm{Cu}_{20} \mathrm{Al}_{10} \mathrm{Ni}_{8} \mathrm{Ti}_{5}$ metallic glass. J Alloys Compd. 2011; 5091011-1019.

[12] Xiong Y, Liu D, Li Y, Zheng B, Haines C, Paras J, et al. Spark plasma sintering of cryomilled nanocrystalline Al alloy - Part I: microstructure evolution. Metall Mater Trans A. 2012; 43A:327-339.

[13] Diouf JS, Fedrizzi A, Molinari A. A fractographic and microstructural analysis of the neck regions of coarse copper particles consolidated by SPS. Powder Technol. 2013; 221:220-227.

[14] Trapp J, Kieback B. Temperature distribution in metallic powder particles during initial stage of field-activated sintering. J Am Ceram Soc. 2015; 98:3547-3552. 
[15] Kuz’mov AV, Olevskii EA, Aleksandrova EV. Effect of micrononuniform heating of powder in field-assisted sintering on shrinkage kinetics. Powder Metall Met Ceram. 2013; 51657-665.

[16] Falcon E, Castaing B. Electrical conductivity in granular media and Branly’s coherer: a simple experiment. Am J Phys. 2005; 73-302-307.

[17] Munir ZA, Anselmi-Tamburini U, Ohyanagi M. The effect of electric field and pressure on the synthesis and consolidation of materials : a review of the spark plasma sintering method. J Mater Sci. 2006; 41:763-777.

[18] Conrad H. Electroplasticity in metals and ceramics. Mater Sci Eng A. 2000; 287:276-287.

[19] Friedman JR, Garay JE, Anselmi-Tamburini U, Munir ZA. Modified interfacial reactions in the Ag-Zn multilayers under the influence of high DC currents. Intermetallics. 2004; 12:589597.

[20] Collard C, Trzaska Z, Durand L, Chaix JM, Monchoux JP. Theoretical and experimental investigations of local overheating at particle contacts in spark plasma sintering. Powder Technol. 2017; 321:458-470.

[21] Molénat G, Durand L, Galy J, Couret A. Temperature control in spark plasma sintering: a FEM approach. J Metall. 2010; 2010:1-9.

[22] Lundström D, Karlsson B, Gustavsson M. Anisotropy in thermal transport properties of cast $\gamma$-TiAl alloys. Zeitschrift für Metallkunde. 2001; 92:1203-1212.

[23] Trzaska Z, Bonnefont G, Fantozzi G, Monchoux JP. Comparison of densification kinetics of a TiAl powder by spark plasma sintering and hot pressing. Acta Mater. 2017; 135:1-13. 
[24] Livesay BR, Donlin NE, Garrison AK, Harris HM, Hubbard JL. Dislocation based mechanisms in electromigration. San Diego, CA: IEEE; 30th Annual Proceedings Reliability Physics; 31 March-2April, 1992: p. 217-227. https://doi.org/ 10.1109/RELPHY.1992.187649.

[25] Conrad H, Sprecher AF, Cao WD, Lu XP. JOM. 1990; 42:28-33.

[26] Trzaska Z, Couret A, Monchoux JP. Spark plasma sintering mechanisms at the necks between TiAl powder particles. Acta Mater. 2016; 118:100-108.

[27] Herzig C, Przeorski T, Mishin Y. Self-diffusion in gamma-TiAl: an experimental study and atomistic calculations. Intermetallics. 1999 7:389-404.

[28] Trzaska Z, Monchoux JP. Electromigration experiments by spark plasma sintering in the silver-zinc system. J Alloys Compd. 2015; 635:142-149. 


\section{Figure Caption List}

Fig. 1. Meshing of the close-packed particle arrangement.

Fig. 2. FEM simulations in metallic particles $100 \mu \mathrm{m}$ in diameter in contact over small areas (contact ratio $\mathrm{r} / \mathrm{R}=0.06$ ) submitted to a constant electric field of $15 \mathrm{~V} / \mathrm{m}$ for $36 \mathrm{~s}$ : (a) current density maps (up: general view, bottom: detail), (b) temperature map.

Fig. 3. FEM temperature maps in metallic powder particles $100 \mu \mathrm{m}$ in diameter heated by hot spots $\left(\mathrm{T} \approx 1000 \mathrm{C}^{\circ}\right)$ at their periphery at $\mathrm{t} \approx 0$ (b), and after $4 \times 10^{-3} \mathrm{~s}(\mathrm{c})$.

Fig. 4. Typical (a) Lamellar and (b) equiaxed microstructures of TiAl processed above and below $1335^{\circ} \mathrm{C}$, respectively. (c) Contact zone between two TiAl powder particles $\approx 100 \mu \mathrm{m}$ in size in a sample processed by SPS at $926^{\circ} \mathrm{C}$. The microstructure of the contact zone in the vicinity of the black arrow remains equiaxed, indicating no overheating above $1335^{\circ} \mathrm{C}$. The white arrow indicates the average direction of the electron of the SPS current flowing though the sample.

Fig. 5. EBSD grain size maps. (a) SPS experiment (densification interrupted at $1148^{\circ} \mathrm{C}$, relative density $\mathrm{D}=0.85$ ). (b) $\mathrm{HP}$ experiment (sample densified at $969^{\circ} \mathrm{C}$ for $15 \mathrm{~min}, \mathrm{D}=0.89$; the distortion of the image which can be noticed comes from the EBSD acquisition in highly tilted $\left(70^{\circ}\right)$ conditions). Note in both cases the concentration of small grains in the neck regions (arrows), as compared to the central regions of the powder particles. Pressure axis: vertical.

Fig. 6. (a) Secondary electron image taken during extraction of a TEM thin foil by FIB in the neck region between two TiAl powder particles. (b) TEM bright field image of a TiAl $\gamma$ grain in a neck region (densification interrupted at $1040^{\circ} \mathrm{C}, \mathrm{D}=0.7$ ). Screw dislocations, helices and loops are indicated by letters S, $\mathrm{H}$ and L, respectively. 
Fig. 7. Relative density (D) as a function of time, for a TiAl powder densified by SPS and HP in identical operating conditions (50 MPa, $\left.20^{\circ} \mathrm{C} / \mathrm{min}\right)$.

Fig. 8. (a-b) SPS set-ups for experiments without current and for artificially increased current. A polymer foil (PEEK, represented in green) protects the diffusion couple from the current (a), or on the contrary, forces all the current to flow through the couple (b). SEM micrographs of reaction experiments $\left(300^{\circ} \mathrm{C}, 5 \mathrm{~min}\right): 0 \mathrm{~A} / \mathrm{cm}^{2}(\mathrm{c})$ and $1060 \mathrm{~A} / \mathrm{cm}^{2}$ (d).

\section{Table Caption List}

Table 1. Meshing parameters. 


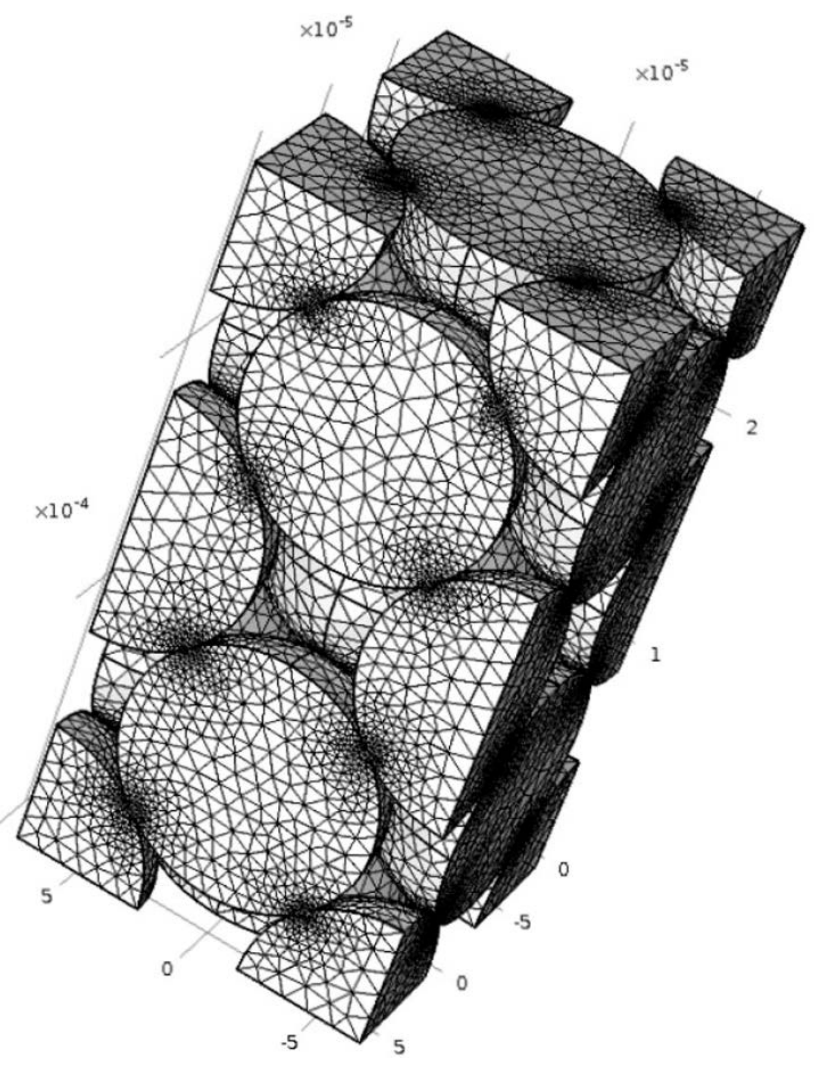

Fig. 1. Meshing of the close-packed particle arrangement. 


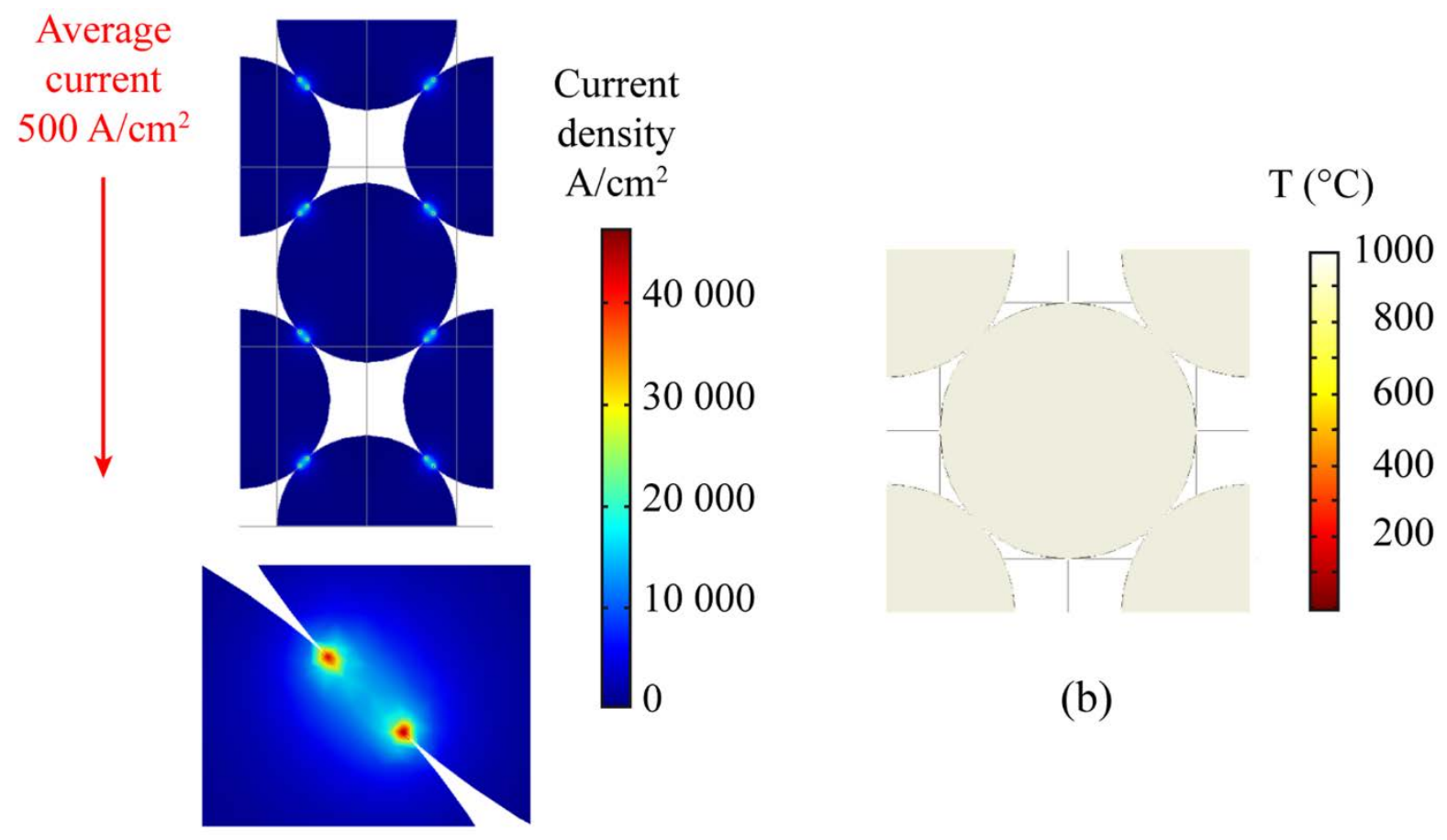

(a)

Fig. 2. FEM simulations in metallic particles $100 \mu \mathrm{m}$ in diameter in contact over small areas (contact ratio $\mathrm{r} / \mathrm{R}=0.06$ ) submitted to a constant electric field of $15 \mathrm{~V} / \mathrm{m}$ for $36 \mathrm{~s}$ : (a) current density maps (up: general view, bottom: detail), (b) temperature map. 


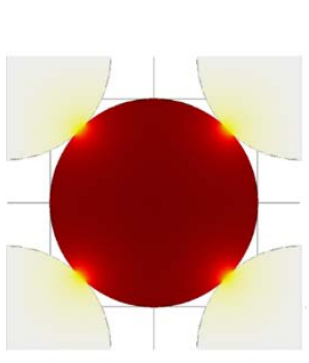

(a)

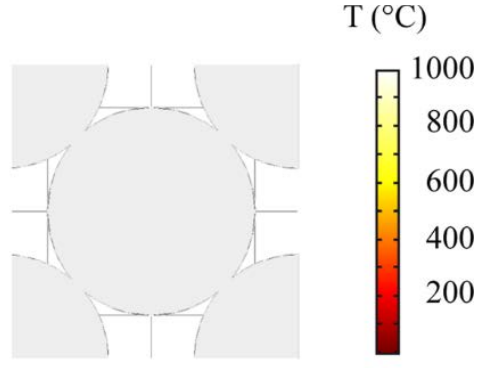

(b)

Fig. 3. FEM temperature maps in metallic powder particles $100 \mu \mathrm{m}$ in diameter heated by hot spots $\left(\mathrm{T} \approx 1000 \mathrm{C}^{\circ}\right)$ at their periphery at $\mathrm{t} \approx 0$ (b), and after $4 \times 10^{-3} \mathrm{~s}(\mathrm{c})$. 

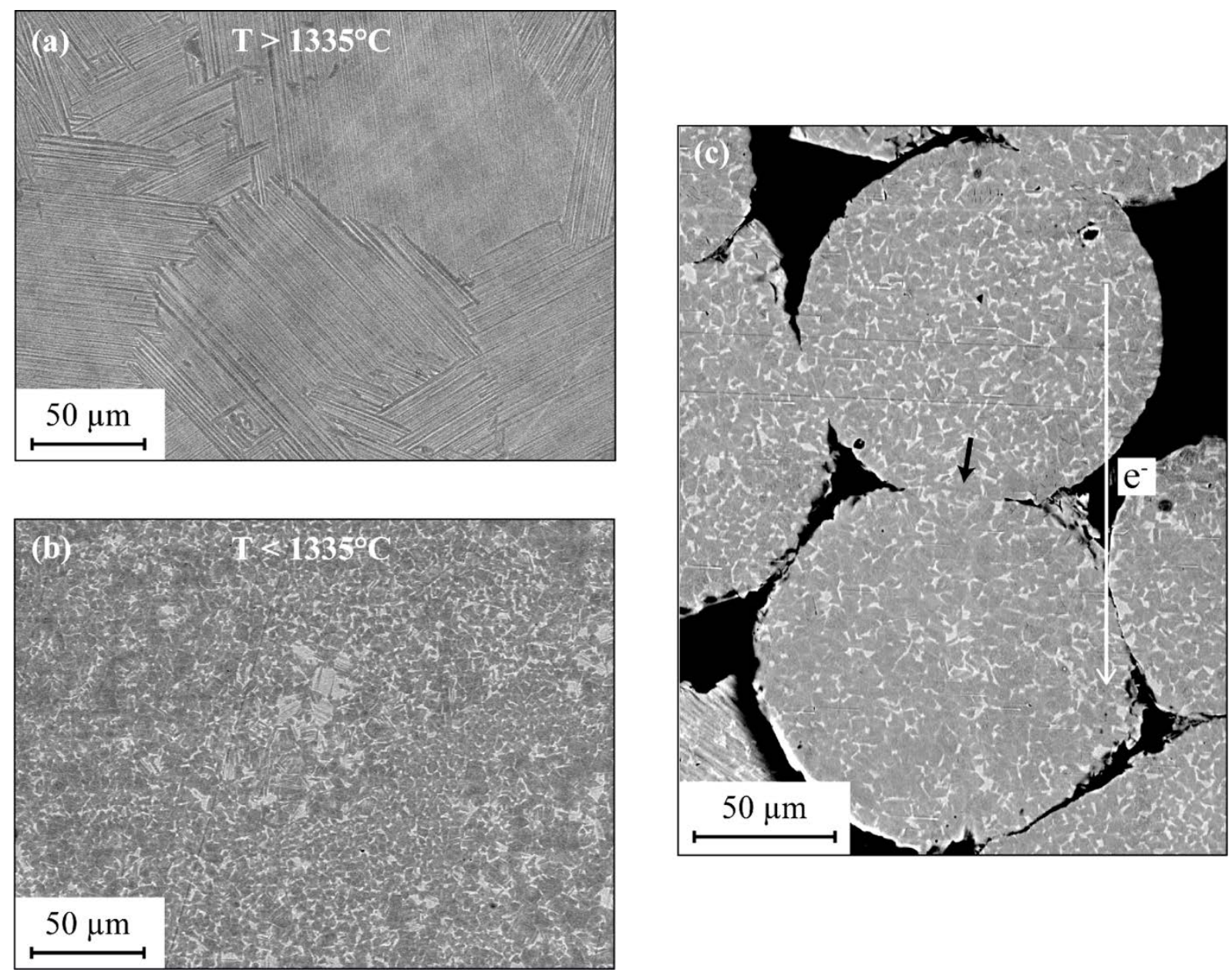

Fig. 4. Typical (a) Lamellar and (b) equiaxed microstructures of TiAl processed above and below $1335^{\circ} \mathrm{C}$, respectively. (c) Contact zone between two TiAl powder particles $\approx 100 \mu \mathrm{m}$ in size in a sample processed by SPS at $926^{\circ} \mathrm{C}$. The microstructure of the contact zone in the vicinity of the black arrow remains equiaxed, indicating no overheating above $1335^{\circ} \mathrm{C}$. The white arrow indicates the average direction of the electron of the SPS current flowing though the sample. 

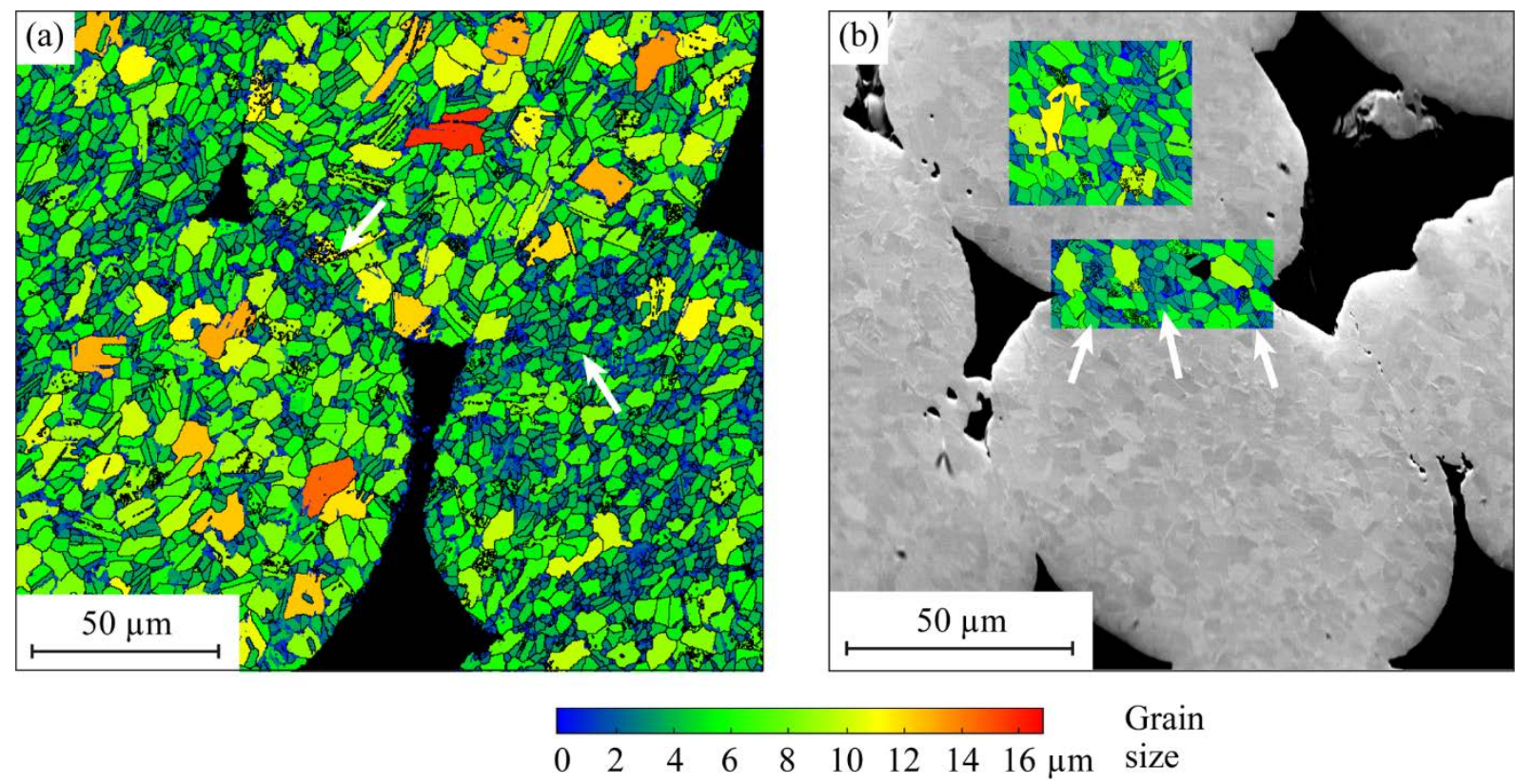

Fig. 5. EBSD grain size maps. (a) SPS experiment (densification interrupted at $1148^{\circ} \mathrm{C}$, relative density $\mathrm{D}=0.85$ ). (b) $\mathrm{HP}$ experiment (sample densified at $969^{\circ} \mathrm{C}$ for $15 \mathrm{~min}, \mathrm{D}=0.89$; the distortion of the image which can be noticed comes from the EBSD acquisition in highly tilted $\left(70^{\circ}\right)$ conditions). Note in both cases the concentration of small grains in the neck regions (arrows), as compared to the central regions of the powder particles. Pressure axis: vertical. 

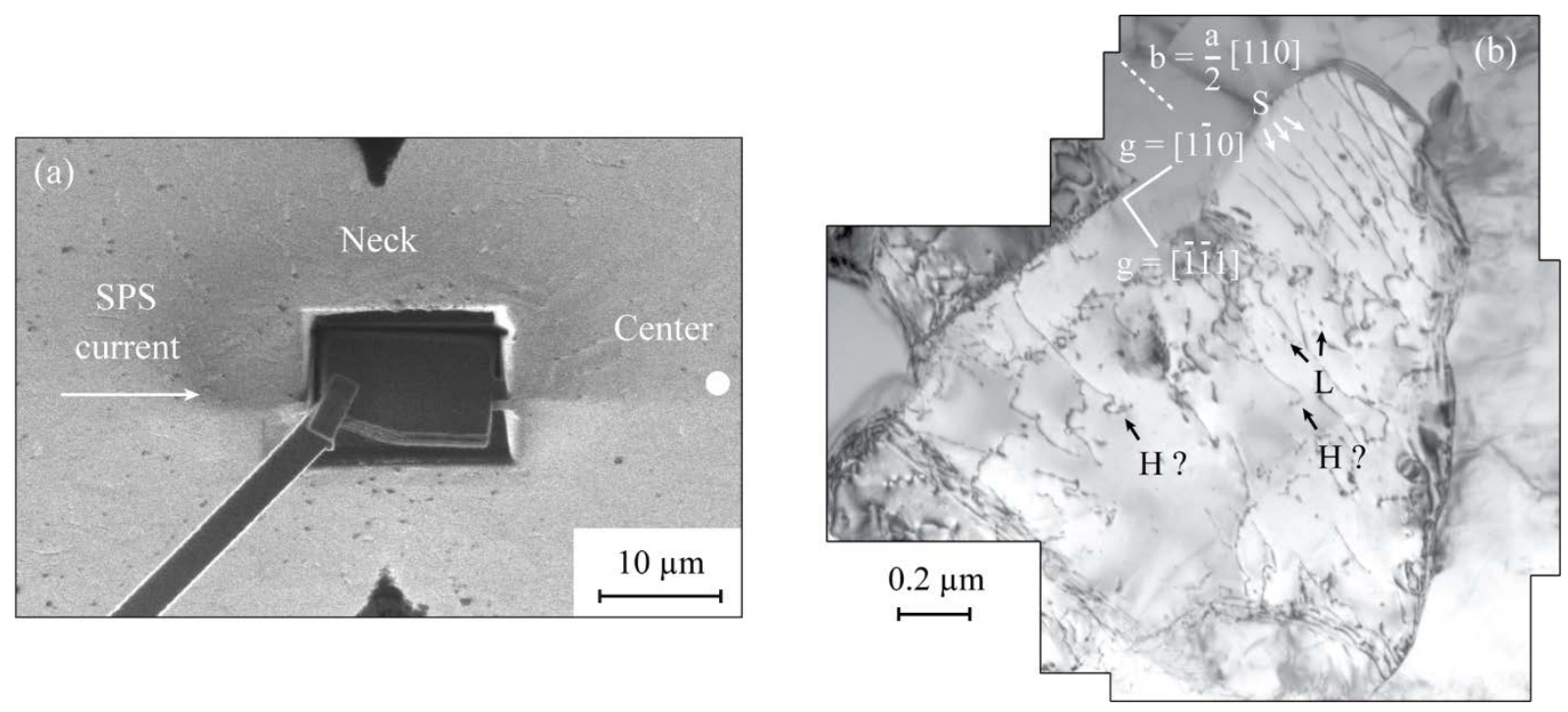

Fig. 6. (a) Secondary electron image taken during extraction of a TEM thin foil by FIB in the neck region between two TiAl powder particles. (b) TEM bright field image of a TiAl $\gamma$ grain in a neck region (densification interrupted at $1040^{\circ} \mathrm{C}, \mathrm{D}=0.7$ ). Screw dislocations, helices and loops are indicated by letters S, H and L, respectively. 


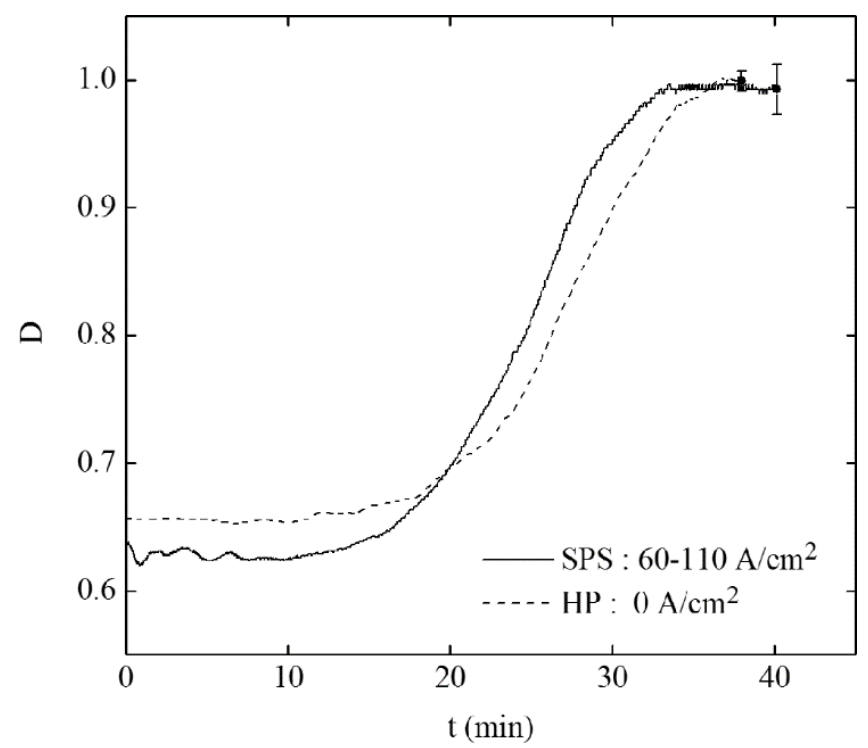

Fig. 7. Relative density (D) as a function of time, for a TiAl powder densified by SPS and HP in identical operating conditions (50 $\left.\mathrm{MPa}, 20^{\circ} \mathrm{C} / \mathrm{min}\right)$. 
$0 \mathrm{~A} / \mathrm{cm}^{2}$

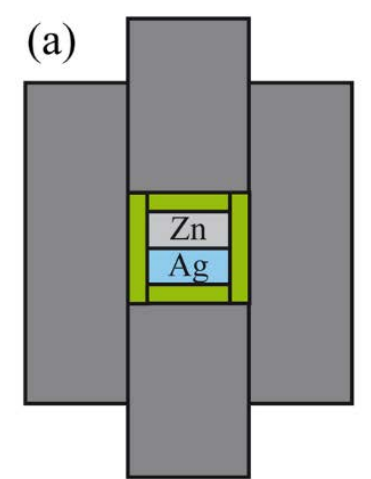

(c)

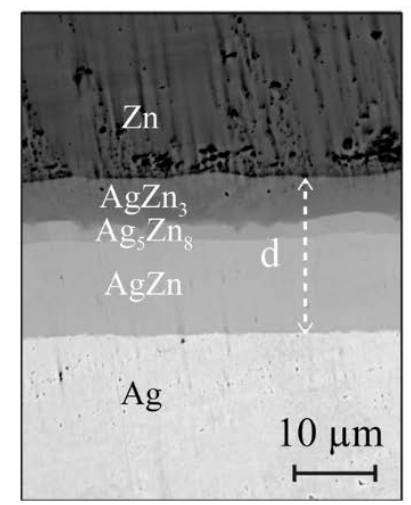

$>1000 \mathrm{~A} / \mathrm{cm}^{2}$

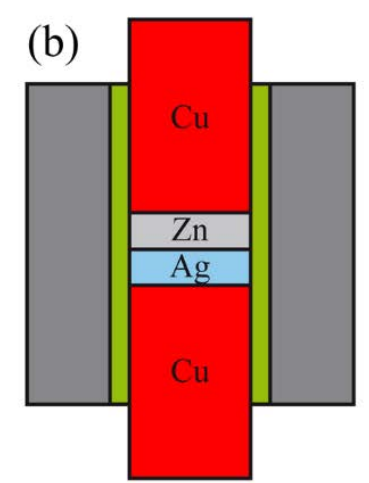

(d)

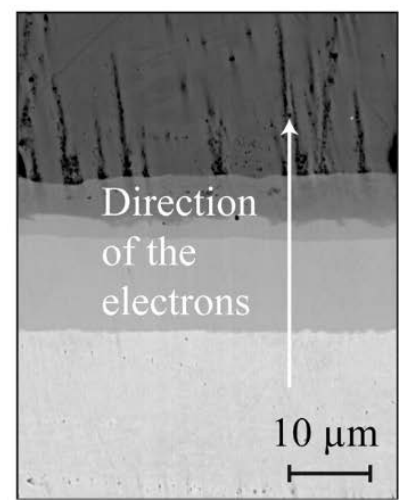

Fig. 8. (a-b) SPS set-ups for experiments without current and for artificially increased current. A polymer foil (PEEK, represented in green) protects the diffusion couple from the current (a), or on the contrary, forces all the current to flow through the couple (b). SEM micrographs of reaction experiments $\left(300^{\circ} \mathrm{C}, 5 \mathrm{~min}\right): 0 \mathrm{~A} / \mathrm{cm}^{2}$ (c) and $1060 \mathrm{~A} / \mathrm{cm}^{2}$ (d). 
Table 1. Meshing parameters.

\begin{tabular}{|l|l|l|}
\hline & Heat conduction problem & Joule heating problem \\
\hline Degrees of freedom & 456,131 & 822,038 \\
\hline Tetraedral elements & 241,812 & $1,004,588$ \\
\hline Triangular elements & 41,948 & 99,614 \\
\hline Edge elements & 3,131 & 5,131 \\
\hline Vertex elements & 240 & 240 \\
\hline
\end{tabular}

